\title{
A AUTONOMIA PRINCIPIALISTA COMPARADA A AUTONOMIA DO LIBERTARISMO
}

\author{
The principialist autonomy \\ compared to libertarian autonomy
}

\author{
Adriano Vieira Schmidtt, Gláucia Rita Tittanegro ${ }^{\mathrm{b}}$
}

\begin{abstract}
a Adriano Vieira Schmidt, Formado em Biologia pela Pontifícia Universidade Católica de Campinas, Especialista em Bioética e Pastoral da Saúde pelo Centro Universitário São Camilo, Mestrando em bioética pela Pontificia Universidad Católica del Chile. Santiago - Chile, email: adrvschmidt@gmail.com

b Gláucia Rita Tittanegro, Doutora em Filosofia pela Pontifícia Universidade Gregoriana de Roma, Coordenadora do Curso de Filosofia e do Curso de Especialização em Bioética e Pastoral da Saúde do Centro Universitário São Camilo, São Paulo, SP - Brasil, e-mail: glaucia@ hotmail.com
\end{abstract}

\section{Resumo}

Este trabalho faz uma análise do princípio da permissão de Engelhardt, e do princípio de respeito à autonomia de Beauchamp e Childress. Por meio de uma análise comparativa desses princípios, e com a intenção de descobrir qual dos dois melhor ajudaria a evitar problemas oriundos de atos moralmente incorretos, discute-se qual deles seria o guia mais indicado para análises de casos concretos no âmbito da Bioética. Inicialmente notase a dificuldade de se chegar a uma resposta muito clara acerca do assunto; entretanto, a análise finalmente nos mostra que a teoria de Beauchamp e Childress seria o guia mais indicado para se resolver os casos concretos.

Palavras-chave: Bioética; Autonomia; Principialismo; Tendências em bioética. 


\begin{abstract}
The present work has the objective of performing and analysis of the permission principle from Engelhardt Jr. and the principle of respect for persons from Beauchamp and Childress. Throughout the analysis of each principle they were both compared regarding which one would be the most helpful in avoiding incorrect moral acts in bioethics issues. Extensive literature research demonstrated the Beauchamp and Childress as the one who mostly adapts as guide of the real cases analysis.
\end{abstract}

Keywords: Bioethics; Autonomy; Principialism; Bioethics tendencys.

\title{
Introdução
}

O surgimento da bioética como uma disciplina de diálogo entre outras muitas disciplinas como filosofia, sociologia, medicina, biologia, teologia veio tentar diminuir um pouco o avanço tecnológico descontrolado e também controlar eticamente as pesquisas envolvendo seres humanos, onde até então, não havia preocupação em relação ao ponto de vista moral.

A bioética tem procurado desenvolver metodologias que possam ser usadas para discutir e solucionar os conflitos morais que surgem no âmbito da saúde e no âmbito científico. A questão fundamental é encontrar métodos de análise que nos ajudem como um guia para um estudo racional, sistemático e objetivo destes problemas, com a intenção de que possamos ter uma tomada de decisão correta e boa (URBAM, 2003, p. 4).

Segundo a definição de Mario Antonio Sanches: "Bioética é a ciência do comportamento moral dos seres humanos diante de toda intervenção da biotecnociência e das ciências da saúde sobre a vida, em toda sua complexidade" (SANCHES, 2004, p. 21).

Depois do Relatório Belmont, os americanos Beauchamp e Childress, publicam o livro Princípios de Ética Biomédica, usando como base os princípios daquele Relatório e agregando-lhe mais um, chamado de 
"princípio da não-maleficência". Criou-se assim, a corrente bioética chamada principialismo, nome dado por Clouser e Gert, em 1990 (GRACIA, 1998, p. 90). Essa corrente é muito discutida e criticada até os dias de hoje, mas ao mesmo tempo, muito usada na prática profissional médica por sua simplicidade e facilidade, ajudando muito na solução de dilemas éticos na clínica (BEAUCHAMP; CHILDRESS, 2002, p. 55).

O método para resolução de dilemas éticos clínicos no principialismo se baseia em quatro princípios: autonomia, beneficência, não-maleficência e justiça. Esse método acaba sendo muito criticado por outras correntes de bioética, sendo uma delas a chamada liberalista, que tem como principal representante o autor H. Tristam Engelhardt, autor do livro Fundamentos de Bioética, onde critica indiretamente o sistema dos quatro princípios e tenta aproximar os chamados "estranhos morais", por meio do princípio da permissão. Esta obra foi, e ainda é, considerada muito polêmica, gerando muitas discussões sobre as idéias ali defendidas.

Nesse seu livro Engelhardt Jr. tenta, por meio do princípio da autonomia, explicar como este mesmo princípio pode servir de base para unir os estranhos morais, pois o respeito ao indivíduo é a única visão comum entre todos os grupos. E é por isso que sua teoria de bioética se baseia fundamentalmente na autonomia (ENGELHARDT Jr., 1996, p. 105).

O crescimento da aceitação da autonomia pelos indivíduos se dá após a imersão destes no político, no econômico e do contexto globalizante que acelera as trocas culturais do sujeito, surgindo, assim, uma reivindicação do individualismo identidário de quem se recusa a mergulhar em uma massa globalizada, aparecendo o princípio da autonomia como um salvador (URBAM, 2003, p. 18). Neste contextom, onde a autonomia se torna um ponto de referência para as diferentes teorias, e, às vezes a base da teoria, faz-se necessário explicar um pouco melhor o que seria a autonomia.

Semanticamente, "autonomia" vem do grego autonomia, palavra formada pelo adjetivo pronominal autos - que significa ao mesmo tempo "o mesmo", "ele mesmo" e "por si mesmo" -, e nomos - que significa "compartilhamento", "lei do compartilhar", "instituição", "uso", "lei", "convenção". Nesse sentido, autonomia significa propriamente a competência humana em "dar-se suas próprias leis”. (SEGRE; SILVA; SCHRAMM, 1998, p. 20). 
Em resumo, ser completamente autônomo ou com determinação própria, ou ainda governo próprio. Indivíduos agem autonomamente, quando são eles mesmos que deliberam sozinhos acerca da ação que vai ser executada, não outros que pediram ou mandaram. Isso seria um exercício interior da liberdade e suas opções de agir são várias, mas somente quando não há coação externa de outrem é que esta ação é completamente autônoma (MAPPES; ZEMBATY, 1991, p. 39).

$\mathrm{Na}$ história da filosofia, vários filósofos discorreram sobre a autonomia, mas os dois conceitos filosóficos da autonomia que mais influenciam os estudiosos de bioética e, em especial, os dois autores que serão estudados ao longo deste trabalho, foram os de Kant e Stuart Mill.

Na vontade Kantiana se desprende a racionalidade do ato, mas a decisão de fazê-lo de forma autônoma ou heterenoma provém da liberdade, que é uma condição do ser humano de caráter transcendental. O outro grande propulsor do princípio da autonomia foi o utilitarista inglês J. S. Mill, que falava da liberdade para se referir ao que Kant chamou autonomia. ${ }^{1}$ (KOTTOW, 1995, p. 74).

Este encontro com a autonomia na área da saúde vem tirando o lugar do chamado paternalismo, substituindo rapidamente a visão Hipocrática de beneficência e dando lugar, quase que completamente, à autonomia, que em alguns países já é dominante, deixando que os pacientes decidam entre as diversas opções de tratamento desejado. Os conceitos de autonomia e autodeterminação do paciente pouco fazem parte da história da ética médica. $\mathrm{O}$ juramento de Hipócrates, por exemplo, nem sequer os menciona: ele se centra no dever de beneficência do médico. (DURANT, 2003, p. 173).

É por causa da importância dada por Engelhardt Jr. e outros estudiosos da bioética, que o objetivo deste trabalho será analisar mais aprofundadamente o princípio da autonomia desenvolvido por este autor, bem como uma comparação ao mesmo princípio elaborado por Beauchamp e Childress,

1 As citações de textos em língua estrangeira neste artigo são traduzidas pelo próprio autor.

Rev. Pistis Prax., Teol. Pastor., Curitiba, v. 1, n. 1, p. 173-198, jan./jun. 2009 
criadores e pertencentes à corrente principialista. É neste contex to de aumento da aceitação do princípio da autonomia e até seu uso como único fundante da moral secular na sociedade, que a análise será mais aprofundada.

A metodologia usada para realizar este trabalho foi uma revisão bibliográfica da literatura existente sobre o tema, assim como artigos científicos publicados nas principais revistas de bioética.

Assim, dentre as diferentes correntes e fundamentações da bioética, o trabalho realizado por Beauchamp e Childress, em Princípios de Ética Biomédica, será usado para se comparar com outro trabalho importante, Fundamentos de Bioética, de H. Tristam Engelhardt, por ser este um trabalho polêmico e ao mesmo tempo inovador (no sentido de que foi um dos primeiros a tentar realizar uma fundamentação filosófica na bioética). Será comparado, então, o princípio da autonomia entre estes dois trabalhos, para assim podermos ver qual dos dois princípios defendidos possui uma estrutura com maior aplicabilidade na bioética, e qual deles tem menos possibilidades de permitir que se realize uma ação incorreta / ilícita. Dessa forma, a visão da autonomia nestas duas diferentes correntes se tornará mais clara, levando a uma melhor compreensão sobre elas.

Ao postular a autonomia como valor bioético, se tenta reduzir precisamente a não-autonomia de todos estes grupos (pacientes, minorias, discriminados, incapacitados $)^{2}$ e recuperar para eles o poder de proteger seus próprios interesses e de tomar decisões independentes em matérias capitalmente importantes para eles. (KOTTOW, 1995, p. 74).

\section{O princípio da permissão em Engelhardt}

Em seu livro intitulado Foundations of Bioethics, Engelhardt Jr.tenta encontrar um meio pelo qual se possa chegar a um consenso ou, ao menos, a um respeito entre as diferentes comunidades morais existentes; Uma sociedade justa, insiste Rawls e os libertarianos, é uma sociedade de máxima liberdade. A liberdade é básica em uma sociedade justa porque é o fundamento da própria estima. O que ele vai chamar de estranhos morais e que representa o pluralismo

Parênteses não encontrado no original. 
moral que nossa sociedade vive nos dias atuais. É a partir da tentativa de encontrar uma forma de consenso entre estes que ENGELHARDT Jr. chega ao seu princípio da permissão e ao princípio da beneficência. $O$ princípio da beneficência não é exigido para cada problema de coerência do mundo moral da bioética. É neste sentido que este princípio não é tão básico quanto aquele que chamarei de princípio da permissão. (ENGELHARDT, 1996, p. 105).

O princípio da permissão vem tentar unir os estranhos morais em um princípio comum no pluralismo moral. "Este princípio (permissão) proporciona o marco formal vazio que possibilita o consenso mútuo em um âmbito secular e pluralista" (BARRERA, 2001, p. 84). Ele surge para tentar responder ou servir de parâmetro para definir uma das bases do porquê uma escolha moral é preferível à outra e tentar definir de forma clara para quem será boa. É claro que nesta questão entrará também o princípio da beneficência, mas aqui, vamos dar prioridade para a análise do primeiro e suas implicações, especialmente porque o próprio Engelhardt Jr. dá prioridade para o princípio da permissão.

Não se pode simplesmente decidir baseando-se nas consequências, para as quais suporíamos verdadeiras as coisas a serem provadas. Necessita-se conhecer, ordenar ou comparar consequências, incluindo-se consequências presentes versus futuras. (ENGELHARDT Jr., 1996, p. 46).

Aqui é mostrada uma crítica direta ao utilitarismo e ao consequencialismo, que segundo ele, não conseguem medir as divergências morais existentes, principalmente porque estas duas correntes éticas não conseguem esclarecer o que é melhor ou pior e para quem. Isso ocorre na medida em que éticas de fundo utilitarista perseguem o prazer e querem tentar avaliar uma ação moral por meio da quantidade de prazer que esta proporciona. Mas, em que ponto a ética de Engelhardt Jr. consegue sair desta problemática e proporcionar um julgamento racional em que seja possível um consenso?

O princípio da permissão é a resposta dada por ele para este conflito. Por meio dela será possível aos estranhos morais chegarem a um mesmo consenso de forma racional: 
Isso reconhece simplesmente aquela autoridade secular e moral de permissão. Esse apelo é a condição mínima para se basear aquilo que é para se resolver emanações de consentimento dentre estranhos morais com autoridade moral. (ENGELHARDT, 1996, p. 69).

Este princípio é construído a partir do princípio da autonomia e serve, de certa forma, de ponto de partida para Engelhardt, já que todas as ações são guiadas pela razão e somente ela pode e deve guiá-las. Mas, com o nome de permissão ele quer mostrar que não somente a razão comanda este princípio, mas este tem em seu núcleo algo da filosofia lockeniana, onde se deve levar em conta o contrato social estipulado entre pessoas e/ou entre as pessoas e o Estado. Este contrato é o consentimento entre as partes conflitantes em um ponto comum onde todos deveriam concordar, mas respeitando a autonomia do outro em suas decisões autônomas e livres.

Esta permissão seria como a condição indispensável para sair das controvérsias éticas, sem recorrer à força, mantendo uma ética secular mínima, destinada ao elogio e à censura. Esse princípio proporciona o marco formal vazio que faz possível o consenso na sociedade secular e pluralista, e constitui a fonte mesma da autoridade moral. Sem o consentimento ou permissão de quem constitui a sociedade plural e secular, não existiria autoridade. (BLÁZQUEZ, 2000, p. 51-52).

O respeito pela autonomia de uma pessoa não deve chegar ao ponto de ferir a de outrem. Este respeito vai até o momento em que o sujeito não age contra este contrato, como seria o caso de pesquisas envolvendo seres humanos sem seu consentimento.

Ninguém pode realizar esses atos sem consentimento dos sujeitos pesquisados, caso contrário estaria ferindo o princípio da permissão. "O indivíduo que viola o princípio da permissão é colocado fora da comunidade pacífica." (ENGELHARDT, 1996, p. 109).

Esta supervalorização do princípio da permissão como base fundamental de uma sociedade pluralista e que não pode chegar a um consenso do que é bom ou ruim, leva Engelhardt Jr. a um campo moral onde as ações não 
podem mais ser vistas como corretas ou incorretas. O próprio autor dá um exemplo para isso: um médico que trabalhava para os nazistas na segunda guerra mundial e que fazia pesquisas utilizando judeus, sem o consentimento destes, não poderia ser visto a partir de outros princípios éticos ou morais como bom ou ruim. "O recurso a este princípio economiza a discussão acerca do que é bom ou mal, independentemente da vontade dos contratantes" (BARRERA, 2001, p. 84). A única coisa que se poderia dizer sobre isto, é que o médico não possuía o consentimento dos indivíduos envolvidos na pesquisa, mas esse é o único ponto em comum com nossa sociedade pela qual podemos avaliar a ação como boa ou ruim (ENGELHARDT, 1996, p. 69).

\section{Análise do princípio da permissão de Engelhardt}

O princípio da permissão tal como está no livro de Engelhardt Jr. mostra, claramente, como ele deve funcionar, mas, para uma análise mais cuidadosa vamos estudar cada ponto do princípio. Podemos, assim, ter uma compreensão detalhada dele e também compará-lo com o princípio da autonomia de Beauchamp e Childress no capítulo 3, deste trabalho. Dessa forma, segue abaixo o princípio tal como está na segunda edição do livro Foundations of Bioethics:

\section{Princípio I - o princípio da permissão:}

a) autoridade pelas ações que envolvem terceiros em uma sociedade pluralista secular vem da permissão deles. Como consequência: i) sem tal permissão ou consentimento não há autoridade; ii)ações contra tal autoridade são reprováveis no sentido de se colocar um transgressor fora da comunidade moral e tornando lícita (mas não obrigatória) uma medida retaliatória, defensiva ou punitiva; consentimento implícito: indivíduos, grupos, e estados possuem autoridade para proteger o inocente contra uma medida indesejada;

b) consentimento explícito: indivíduos, grupos e estados podem impor decisões sobre contratos ou criar direitos acerca do bem estar social;

c) justificativa do princípio: o princípio da permissão expressa a circunstância na qual a autoridade para resolver as disputas morais em uma sociedade secular e pluralista pode vir somente do acordo 
entre participantes, desde que ela não venha de argumento racional ou crença comum. Portanto, permissão ou consentimento é a condição necessária para haver uma comunidade moral. O princípio da permissão proporciona o meio menos prolixo para se estabelecer a descrição de uma sociedade moral. Isso é tão indispensável quanto o interesse de pessoas em condenar ou louvar com justificativa e tomar decisões com autoridade moral;

d) a motivação para obedecer ao princípio está amarrada a interesses que agem de uma maneira: i) que geralmente é justificável para pessoas pacíficas, e ii) que não justificaria o uso de atitude defensiva ou punitiva contra alguém;

e) implicações para políticas publicas: o princípio da permissão proporciona bases morais para políticas públicas cujo objetivo é defender o inocente;

f) máxima: não faça a outros aquilo que eles não fariam para eles mesmos, e faça a eles aquilo que cada um é contratado para fazer;

g) o princípio da permissão baseia-se naquilo que pode ser chamado de moralidade da autonomia como o respeito mútuo. (ENGELHARDT, 1996, p. 122-123).

Na primeira parte, Engelhardt Jr. explicita o princípio da permissão pelo qual uma pessoa somente tem autoridade para realizar alguma ação envolvendo outro sujeito, se esta ação estiver de acordo com a permissão dada entre eles. E, assim, deriva-se diretamente que se este agente 1 age sem a permissão do sujeito 2 , então esta ação não é boa, é uma ação não autorizada. No caso de ações que não possuem a permissão entre os sujeitos, comete-se um ato contra a comunidade em geral, já que não existe o consenso para este ato, tornando-o ilícito e permitindo assim a punição do agente.

Nos itens A e B ele classifica dois tipos de consentimentos que servem para um individuo, um grupo ou comunidade e para o próprio Estado. O primeiro (a) é o chamado consentimento implícito, onde todos os sujeitos envolvidos tem poder para proteger qualquer outro sujeito contra abusos ou atos não consentidos. Este item tem como função principal defender e manter o consentimento da sociedade. Já no item (b), que é o chamado consentimento explícito, os sujeitos podem forçar a aceitação de certos consensos. Um exemplo deste caso é o próprio Estado que estipula leis para uma melhor harmonia da sociedade como um todo. 
No item (c) aparece a justificativa do princípio que, como já foi comentado anteriormente, seria para resolver disputas morais em uma sociedade pluralista por meio do consenso ou consentimento, sempre que, de alguma forma, estas não possam ser resolvidas por meio de argumentos racionais. O consenso ou consentimento seria, então, uma condição necessária para a comunidade moral. O princípio da permissão seria o denominador comum entre as diferentes pessoas em uma sociedade pluralista; ele seria o único ponto que poderia ajudar a manter a sociedade e a boa convivência dentro dela, pois é o meio pelo qual as pessoas poderiam ter autoridade moral sobre as ações realizadas.

No item (d) colocam-se os motivos pelos quais se deve obedecer ao princípio da permissão. Essa obediência tem fundamento no sentido em que serve para manter a boa convivência entre as pessoas, já que vai garantir uma forma de ação que seja aceitável para toda a comunidade. Mas isso não tem validade em ações que afetem somente o próprio agente porque nesta ação a comunidade não será afetada, ou seja, permite o suicídio ou eutanásia, sem que com isso a sociedade mesma possa se expressar, pois a ação não afeta ninguém, o que a torna aceitável. Estes atos poderiam ser uma forma de realizar plenamente a autonomia do sujeito.

No item (e) ressaltam-se as implicâncias políticas do princípio, o qual permite um direcionamento das políticas morais para a defesa da pessoa considerada inocente, ou seja, defende as pessoas que seguem o princípio da permissão.

No item (f) é feita uma descrição do princípio na forma de uma máxima: não se deve fazer ao outro o que o outro não faria a si mesmo, e que se deve fazer ao outro o que se está contratado para fazer. Aqui se nota que o princípio desenvolvido por Engelhardt Jr. tem uma clara base contratualista e, mesmo sendo este autor colocado na corrente liberalista da bioética, ele apresenta esta característica explicitamente.

No item (g), Engelhardt Jr. mostra como foi que se chegou ao princípio da permissão: "O princípio da permissão baseia-se naquilo que pode ser chamado de moralidade da autonomia, como o respeito mútuo" (ENGELHARDT Jr., 1996, p. 123). Ou seja, o princípio vem diretamente do conceito de autonomia, mas com uma concepção um pouco diferente das concepções usadas na filosofia, onde o correto e o incorreto são ditados pela própria razão, e aqui, se usa os termos bem e mal que provém do contrato entre as pessoas. 


\section{O princípio de respeito à autonomia}

O livro Princípios de Ética Biomédica, de Beauchamp e Childress, na realidade se dedica à ética médica de uma forma geral, mas acabou sendo um dos mais importantes livros de bioética. "Todas as outras teorias foram construídas até os dias de hoje em diálogo com esta, em seu favor ou contra ela" (GRACIA, 1998, p. 90). Neste livro, os autores tratam sobre os quatro princípios básicos para a ética biomédica e, hoje, para a bioética também. São eles: o Princípio de Respeito à Autonomia, o da Não-Maleficência, o da Beneficência e o da Justiça. "[...] na legitimação desses princípios; eles são tomados tal como enunciados, tal como encontrados na moral social comum" (DURANT, 2003, p. 51). Os autores tem a intenção de tentar desenvolver um mecanismo que ajude as decisões morais entre as diferentes comunidades, não importando à qual corrente ética elas pertençam, criando assim um método prático de ajuda para estes (BEAUCHAMP; CHILDRESS, 2002).

Estes quatro princípios são prima facie obrigatórios, usando um conceito tirado de W. Ross:

De acordo com Ross, em cada circunstância devemos encontrar o melhor dever, encontrando 'o maior equilibrio' do justo sobre o injusto em cada contexto concreto. Ross introduz então, sua distinção central entre deveres prima facie e deveres efetivos: o 'dever prima facie' é um dever que sempre tem que ser cumprido, a não ser que entre em conflito em um determinado caso, com um dever igual ou mais forte. (BEAUCHAMP; MCCULLOUGH, 1987, p. 13).

O que quer dizer que eles não possuem em sua estrutura uma ordem de importância ou de grau, evitando-se assim normas absolutas, rígidas e que prevalecem iguais em todos os casos (BEAUCHAMP; CHILDRESS, 2002).

Este método dos princípios é muito criticado por outros autores, principalmente porque os princípios não possuem em sua formulação um vínculo com leis morais ou qualquer aprofundamento ético em sua estrutura (KOTTOW, 1995 p. 53). Em sua quarta edição (como uma resposta às críticas), introduziuse um acréscimo de condições para se aplicar o método dos princípios, tentando, assim, evitar o problema no processo de ponderação, que foi considerado muito intuitivo para que se pudesse justificar a infração de algum dos princípios. Estas condições, assim como os próprios princípios, também são prima facie. 
1) Podem ser oferecidas razões melhores para agir de acordo com a norma prioritária do que com a norma que está sendo infringida (por exemplo, se certas pessoas tem um direito, seus interesses merecem um lugar especial ao serem ponderadas contra os interesses de pessoas que não possuem um direito equivalente);

2) O objetivo moral de justificar a infração possui uma expectativa realista de ser alcançado;

3) Não se pode substituir o ato por nenhuma alternativa moralmente preferível;

4) A forma de infração escolhida é a menor possível, comparada com a obtenção do objetivo primordial da ação;

5) O agente procura minimizar os efeitos negativos da infração. (BEAUCHAMP; CHILDRESS, 2002, p. 52).

As condições apresentadas são como uma ajuda para decidir qual princípio deve prevalecer ou a qual se deve dar maior importância, assim, estas condições serviriam para um uso posterior ao da identificação dos princípios que estão presentes ou em conflito. Mesmo assim, a teoria dos autores continua bastante aberta e simples, mantendo a praticidade da aplicação dos princípios nos casos práticos. A intenção dos autores não é a criação de um sistema perfeito que resolva qualquer dilema moral existente, a idéia é que esta sirva de ajuda nos dilemas morais (BEAUCHAMP; CHILDRESS, 2002, p. 49).

Por agora, vamos analisar com maior profundidade o princípio de respeito à autonomia, mesmo que este, na teoria de Childress, não dê prioridade a nenhum princípio em especial, porque são todos prima facie. Mas, para este trabalho será de extrema importância sua análise, para que posteriormente seja possível a comparação deste princípio com o princípio de Engelhardt.

\section{Análise direta do princípio de respeito à autonomia}

O princípio proposto por Childress, não é em si mesmo um princípio, mas uma lista de considerações, sem um conceito preciso do que representa este princípio e também sem uma definição única (KUCZEWSKI, 1998, p. 522).

Childress começa definindo o que seria a autonomia para um indivíduo qualquer: 
O governo pessoal do eu que é livre de inferências controladoras por parte de outros, como limitações pessoais que obstam a escolha expressiva da intenção, tais como a compreensão inadequada. (BEAUCHAMP; CHILDRESS, 2002, p. 138).

Nesta passagem, Childress focaliza a autonomia em seu conceito mais puro, baseado na livre escolha do indivíduo, sem que este receba qualquer tipo de coerção ou influência externa a ele mesmo. O princípio de respeito à autonomia, não é a mesma coisa que ser autônomo, este respeito seria um reconhecimento de que outras pessoas tem diferenças, respeitando-as.

Ser autônomo não é a mesma coisa que ser respeitado como um agente autônomo. Respeitar um agente autônomo é, no mínimo, reconhecer o direito dessa pessoa de ter suas opiniões, fazer suas escolhas e agir com base em valores e crenças pessoais. Esse respeito envolve a ação respeitosa, e não meramente uma atitude respeitosa. (BEAUCHAMP; CHILDRESS, 2002, p. 142).

O respeito seria, então, uma forma de tratar as outras pessoas, dando a elas a oportunidade de agir autonomamente. Um desrespeito seria vedar aos outros indivíduos a possibilidade de agir ou pensar conforme queiram. Seria, neste caso, negar a igualdade entre as pessoas, impondo suas próprias convicções ou valores.

O princípio de respeito à autonomia pode ser estabelecido em sua forma negativa, da seguinte maneira: as ações autônomas não devem estar sujeitas a pressões controladoras de outros. O princípio exige uma obrigação ampla e abstrata que é livre de cláusulas restritivas, tais como "devemos respeitar as opiniões e os direitos dos indivíduos desde que seus pensamentos e ações não prejudiquem outras pessoas seriamente". O direito de autodeterminação, que sustenta vários direitos de autonomia, incluindo os de confidencialidade e privacidade, é correlato a essa obrigação. (BEAUCHAMP; CHILDRESS, 2002, p. 143).

Esse princípio origina-se diretamente da concepção de respeito à autonomia de Kant e de Stuart Mill. Mesmo estes dois filósofos, tendo filosofias bastante distintas apóiam o respeito à autonomia (BEAUCHAMP; CHILDRESS, 2002, p. 143). O imperativo prático será então: age de tal 
modo que te relaciones com a humanidade, tanto na sua pessoa, como na de qualquer outro, sempre como um fim, nunca somente como um meio. (KANT, 2001, p. 104).

\section{Princípio de respeito à autonomia ${ }^{3}$}

a) As ações autônomas não devem estar sujeitas a pressões controladoras de outros indivíduos.

b) Não é a única fonte de direitos do indivíduo.

c) Regras derivadas (estas regras também são prima facie):

1. dizer a verdade;

2. respeitar a privacidade dos outros;

3. proteger informações confidenciais;

4. obter consentimento para intervenções nos pacientes;

5. quando solicitado, ajudar os outros a tomar decisões importantes (BEAUCHAMP; CHILDRESS, 2002, p. 145).

d) A quem não se aplica: pessoas imaturas, inaptas, ignorantes, coagidas ou exploradas (crianças, indivíduos irracionalmente suicidas, dependentes de drogas, indivíduos com problemas mentais, etc).

e) Justificação: todas as pessoas tem o direito de exercer sua autonomia de forma livre e sem coerção e se possível ajudar para que outros possam exercê-la da mesma forma, igualando, assim, os direitos e o respeito dos indivíduos.

f) Máxima: "as ações autônomas não devem estar submetidas à limitações controladas por outros.” (LOLAS, 1998, p. 52).

No item A, se passa a idéia de que todas as pessoas devem ter direito a pensar e agir como quiserem e não devem sofrer coerções de nenhum tipo por parte de outros; o indivíduo deve poder exercer por completo sua autonomia.

O princípio de respeito à autonomia não deve ser considerado a única fonte de direitos dos indivíduos, pois se ele fosse a única fonte, os outros princípios, apresentados por Childress, teriam um caráter derivado diretamente

3 Esquematização construída pelo próprio autor para facilitar a visualização e interpretação do princípio de respeito à autonomia.

Rev. Pistis Prax., Teol. Pastor., Curitiba, v. 1, n. 1, p. 173-198, jan./jun. 2009 
deste princípio, impossibilitando todo o sistema apresentado pelo autor e também não permitindo o uso de princípios prima facie, já que este princípio seria o de maior valor para a teoria.

As Regras derivadas, mostradas no item C, são atitudes que derivam diretamente do princípio de respeito à autonomia, e são ações não só para os que trabalham na área biomédica, mas também foram especialmente colocadas para o uso em diversas situações na área da saúde.

[...] Se os valores do paciente se confrontam diretamente com as da medicina, a responsabilidade fundamental dos médicos se baseia em respeitar e facilitar uma auto-determinação do paciente na tomada de decisões sobre seu destino médico. As obrigações e virtudes do médico nascem, portanto, do Princípio de Respeito à Autonomia. (BEAUCHAMP; MCCULLOUGH, 1987, p. 45).

A autonomia não é um princípio do qual todos os indivíduos desfrutam. No item D, se apresentam alguns exemplos de pessoas com autonomia restringida ou nula. Os fatores que interferem na autonomia podem ser de diversos tipos e naturezas. Sendo assim, é importante se avaliar em cada caso especifico, se a pessoa é ou não capaz de expressar sua autonomia de forma completa ou incompleta. Isto não quer dizer que uma pessoa avaliada como possuidora de uma autonomia restringida não possa tomar decisões sobre algumas questões em relação ao rumo de sua vida ou outras decisões autônomas mais baixas. Por medo da perda de autonomia por alguma razão, hoje em dia, ao menos nos Estados Unidos, é muito comum encontrar o chamado Living will.

No item E, se justifica o porquê de existir o princípio da autonomia. Ele existe e é importante porque não só garante a liberdade de pensamento e de agir de um indivíduo, mas também se caracteriza por fazer com que outros participem e ajudem no desenvolvimento da autonomia de um indivíduo com autonomia restringida ou em desenvolvimento.

No item F, é a máxima, do princípio em sua forma negativa, é assim expressado, pois não existe uma forma de expor uma máxima positiva para este princípio, e a partir dela se percebe o quão importante é o respeitar a autonomia dentro da teoria de Beauchamp. As ações não devem ser controladas por fatores externos, mas isso não significa uma falta total de controle, o controle se dá por meio de outros princípios existentes. 


\section{Comparação entre os dois princípios}

Os dois princípios descritos anteriormente já começam a se diferenciar um do outro pelo próprio nome, sendo um chamado de Princípio da Permissão e o outro de Princípio do Respeito à Autonomia. Por meio desta diferença de nome, os autores pretendem explicitar, já nesta nomenclatura, a principal característica de cada um. O primeiro, o Princípio da Permissão, tem este nome para ressaltar que não é uma liberdade e autonomia plena, mas sim um compromisso contratual dos agentes envolvidos na ação.

Como um passo no sentido de evitar confusão, eu rebatizei nesta segunda edição "princípio da autonomia" com o nome "princípio da permissão" para melhor indicar que o que está sendo questionado não é nenhum valor possuído pela autonomia ou liberdade, mas o reconhecimento de que a autoridade moral secular vem da permissão daqueles que estão envolvidos em um engajamento comum. (ENGELHARDT, 1996, p. 11).

Já o Princípio do Respeito à Autonomia, explicita que também não está baseado somente na autonomia, mas principalmente no respeito a esta.

Ser autônomo não é a mesma coisa que ser respeitado como um agente autônomo. Respeitar um agente autônomo é, no mínimo, reconhecer o direito dessa pessoa de ter suas opiniões, fazer suas escolhas e agir com base em valores e crenças pessoais. Esse respeito envolve a ação respeitosa, e não meramente uma atitude respeitosa. (BEAUCHAMP; CHILDRESS, 2002, p. 142).

\section{Os princípios vistos a partir de sua máxima}

As duas teorias possuem uma máxima. Em Engelhardt Jr. ela se encontra em sua forma positiva, na qual o dever das pessoas é o de não realizar nenhuma ação que a outra pessoa não deseje ou não queira, uma somente está autorizada a realizar algum ato para a outra, quando o contrato entre estas já está claro.

Em Beauchamp, encontramos a forma negativa da máxima. Por meio desta forma a idéia é a de aumentar a importância do respeito à autonomia do próximo. Não existe nesta máxima nada que obrigue por completo a respeitá-la, mas também não possui em sua estrutura nada que desobrigue o seu cumprimento. 


\section{Os princípios em relação à sua importância dentro da teoria}

Em Beauchamp, o princípio do respeito à autonomia, é considerado prima facie obrigatório, que seria a qualidade de poder suprimi-lo no caso de existir algum princípio de maior relevância envolvido. Ele não passa de um princípio a mais na teoria de Beauchamp, não possui nenhuma prioridade clara sobre os outros e trabalha conjuntamente com os outros princípios (nãomaleficência, beneficência e justiça).

Já, o Princípio de Permissão de Engelhardt, é um princípio básico, pois é a base de todos os outros. Estes se derivam diretamente do princípio de permissão, que funciona como um princípio neutro, pelo qual todas as pessoas, por mais diferentes que sejam moralmente, podem chegar a um consenso comum.

A proposta principal de todas estas correntes é que a moral não se pode fundamentar nem nos fatos, nem nos valores objetivos ou transcendentes, mas somente na 'opção' autônoma do sujeito. Em outras palavras, partese do não-cognitivismo, ou seja, da impossibilidade de conhecer os valores. (SGRECCIA, 1996, p. 66).

Essa primazia extrema do princípio de permissão leva a problemas em identificar quais ações são moralmente corretas ou não, porque este princípio somente identifica o que seria aceito ou não pelo indivíduo, permitindo assim, ações moralmente incorretas.

\section{Os princípios quanto à derivação de direitos}

O princípio de permissão é a base para se derivar a maioria dos direitos. Não se pode, segundo Engelhardt, derivar os direitos, por exemplo, do princípio da beneficência, porque este é relativo para as diferentes comunidades morais existentes. A idéia do que é bom é relativo, o que é bom para uma comunidade pode não ser para outra. Neste sentido, que o princípio de permissão é a base dos direitos, pois estes somente podem ser criados de acordo com o consenso ou permissão entre os indivíduos, fazendo deste princípio o denominador comum entre as comunidades.

O princípio do respeito à autonomia possui alguns direitos derivados, mas não é o único princípio do qual podem se derivar direitos, pois sua importância pode ser secundária ou até nula em alguns casos. Por isso, na visão de Beauchamp, os direitos das pessoas devem se derivar do grupo dos quatro princípios como um todo e não somente de um princípio. 


\section{A que tipos de pessoas estes princípios servem}

No princípio formulado por Engelhardt, se estabelece que somente pessoas racionais possam usufruir o direito deste princípio. Isso quer dizer que uma criança, um neonato, um sujeito com sérios distúrbios mentais ou senis com alguma doença degenerativa cerebral, não podem usufruir por completo deste princípio.

Na teoria de Engelhardt, os contratos e consensos são a base de toda obrigação moral em um mundo secularizado e podem ser feitos somente por 'pessoas', pois que elas são seres autoconscientes, racionais, livres para escolher, e em posse do senso moral concernente. (HANSON, 2005, p. 179).

Este ponto da teoria de Engelhardt Jr. é muito perigoso, podendo gerar uma série de ações que parecem até irracionais, mas que, de acordo com esta teoria, podem ser levadas a cabo se existir consenso, como o infanticídio, a eutanásia, entre outros.

No princípio de respeito à autonomia, Beauchamp considera qualquer pessoa detentora do direito de usufruir desta autonomia em graus compatíveis com sua condição. Por exemplo, uma criança tem o direito de que seja respeitada sua autonomia se a decisão em questão não for de muita importância. Qualquer pessoa tem o direito de receber o respeito por sua autonomia, mas algumas tem este direito limitado, a chamada autonomia restringida. Aqui, a falta de autonomia de alguns sujeitos não é motivo para que se permitam certas ações contra eles, pois o princípio de mais peso poderá não ser o do respeito à autonomia, garantindo, assim, a proteção de sujeitos com autonomia restringida ou nula.

Na teoria de Beauchamp, a autonomia do sujeito ou desaparece, dando lugar a outros princípios, ou se mantém, mas sempre em conformidade com outros princípios. Esta teoria sempre está na balança com o paternalismo de um lado e a autonomia do outro, e se torna muito difícil, em alguns casos, determinar onde acaba a autonomia e onde deve começar o paternalismo.

Estas forças confluíram para criar desconfiança no paternalismo tradicional do médico e exigem autodeterminação e consentimento informado nas relações médicas. A autonomia se converteu na insígnia 
que simboliza o direito moral e legal dos pacientes ao adotarem suas próprias decisões sem restrição nem coerção, por mais benfeitoras que fossem as intenções do médico. (PELLEGRINO, 1990, p. 9).

\section{Quanto à base de fundamentação do princípio}

O princípio desenvolvido por Engelhardt Jr. tem sua base formulada diretamente na teoria de John Rawls, em que este apóia a justiça ligada estritamente à liberdade individual, sendo assim um dos marcos da teoria libertária. Uma teoria justa, insistem Rawls e os libertarianos, é a base para uma sociedade de máxima liberdade. A liberdade é básica em uma sociedade justa porque ela é o fundamento da própria estima (ENGELHARDT Jr., 1996, p. 122).

Engelhardt Jr. une este conceito de liberdade com o conceito kantiano de autonomia que o próprio Rawls usa em seu livro Theory of Justice e, a partir disso, constrói então toda a concepção do princípio de permissão, sua característica de ser o centro da teoria faz com que seja considerado, por Engelhardt Jr. a base de uma sociedade justa.

Quando as leis não respeitam os limites naturais ou o Estado exagera em suas funções e ultrapassa os poderes que outorgaram a ele no contrato social, então, existe injustiça. Aqui está afinal, o que, segundo o pensamento liberal, deve se entender por justiça da liberdade contratual ou pelo contrato que assegure e proteja a liberdade individual. (GRACIA, 1990, p. 190).

No princípio de Beauchamp, pode-se notar uma forte referência ao princípio da autonomia trazido pelo Relatório Belmont, que teve grande influência no trabalho deste, pois este relatório já tinha o que seria um esboço mais ou menos acabado deste princípio.

Respeito pelas pessoas: o respeito pelas pessoas incorpora ao menos duas convicções éticas; primeira, aqueles indivíduos que devem ser tratados como agentes autônomos, e segundo, aquelas pessoas para as quais se deve garantir a proteção por possuírem a autonomia diminuída. $\mathrm{O}$ princípio de respeito para com as pessoas tem duas implicações morais: a de reconhecer a autonomia e a de proteger aquelas com a autonomia diminuída. (BEAUCHAMP; CHILRESS, 2002, p. 325). 
Baseado no conceito de autonomia deste relatório é que Beauchamp vai chegar à sua formulação do princípio do respeito à autonomia, que é muito parecido com esta descrição acima e, de certa forma, somente continua o que o Relatório Belmont já havia começado. É por se basear neste relatório e não esclarecer por completo a definição dos princípios citados no livro Princípios de Ética Biomédica, que muitos críticos veem esta teoria como errada ou carente de fundamentação. Aqui os princípios são considerados como orientações que não se excluem da análise ética e que devem aceitar a crítica de não estarem baseados em leis morais absolutamente válidas (KOTTOW, 1995, p. 72).

\section{As duas formulações do princípio mostrando suas diferenças na prática}

Ainda que as duas sejam baseadas no princípio da autonomia, suas diferenças na prática vão aparecer mais claramente devido à importância dada por cada autor ao seu princípio.

Analisaremos o caso ${ }^{4}$ de uma mulher jovem de cerca de 30 anos, que se recusa completamente a ter um filho. Sua gravidez já está nas últimas semanas e os motivos apresentados por esta mulher para não ter o filho são além de estéticos, a falta de paciência com crianças. Ela se encontra em um Estado onde o aborto é permitido em qualquer situação.

Em uma análise pela teoria de Engelhardt, o princípio de permissão é dominante e base para as demais ações. Nesta teoria, se esta mulher encontrar um médico disposto a realizar este aborto "estético", este ato será realizado sem maiores preocupações com a criança ou com as concepções morais se a ação é lícita ou ilícita. A criança por não possuir ainda uma racionalidade que the permita exercer sua autonomia, não possui direitos na sociedade, transformando-se em um objeto do ponto de vista da "moral secular". Sendo assim, este aborto seria realizado sem uma concepção ética, pois o Estado já deu o seu consenso neste assunto. Ao realizar este aborto, esta mulher de forma alguma estaria ferindo algum princípio bioético de Engelhardt. Pelo contrário, estaria agindo de acordo com o contrato social, não sendo necessária neste ponto a discussão do eticamente correto ou incorreto.

4 Este caso é totalmente fictício e foi colocado pelo próprio autor somente para deixar mais claro as possibilidades de ação dentro das duas teorias. 
O relativismo pode tomar também uma forma completamente diferente, a qual seria perfeitamente compatível com o reconhecimento da objetividade da verdade mesmo acerca do que é bom. Essa forma de relativismo ético consiste na visão de que o único tipo de bondade existente é subjetivamente satisfeita ou não satisfeita. Sobre esse tipo de 'bem' ou importância positiva (o agradável ou desagradável), todos nós aceitamos que é relativo, como se viu nos capítulos precedentes. Comer gorgonzola, por exemplo, é prazeroso para uma pessoa e detestável para outra. O valor do relativismo deveria, então, significar que todos os 'bens', incluindo o bem moral depende do gosto subjetivo e todos os bens são apenas os que subjetivamente se gostam ou não. (SEIFERT, 2004, p. 245).

No caso da análise direta pela teoria de Beauchamp, o caso pode chegar a ser levado até as últimas consequências, mas como o princípio do respeito à autonomia é prima facie obrigatório, provavelmente vai se partir para algum outro princípio mais relevante, pois existe a criança também e mesmo que ela não possa se afirmar ainda como pessoa, esta criança é considerada, deixandose assim o princípio do respeito à autonomia para que prevaleça o princípio da não-maleficência para a criança, pois o procedimento estético é de menor importância se comparado à vida da criança que está para nascer. Sendo assim, o princípio da autonomia é trocado por outro princípio mais forte e necessário.

Assim, a peça central do principialismo 'o princípio da autonomia', incorpora um perigoso nível de confusão. Essa confusão é criada pela falta de claridade no que se entende por ação autônoma e escolhas, e atenuando a distinção da base moral, entre regras morais e ideais morais. (GERT; CULVER; CLOUSER, 1997, p. 81).

A teoria de Beauchamp não consegue escapar das críticas e, principalmente, da crítica sobre a falta de fundamentação em seus princípios. Sua definição de autonomia é muito obscura e não consegue explicitar sua idéia sobre o que ela é ou como funciona ao certo.

Com a aplicação que supõe contar com um conjunto de princípios reduzíveis a regras práticas, e estas a casos e situações, não se deve esquecer que os princípios, enquanto tais, não podem indicar quando se aplicam, nem como se aplicam. São de um nível intermediário, ou seja, se encontram entre as grandes generalizações filosóficas e as regras de conduta, de modo que sua interpretação e aplicabilidade dependem de fatores que não se encontram neles mesmos (LOLAS, 1998, p. 49). 


\section{Conclusão}

É notável a diferença entre os dois princípios analisados neste trabalho. Mesmo os dois se baseando inicialmente no princípio da autonomia, apresentam desigualdades gritantes. Isso acontece devido ao simples grau de importância colocado em cada uma das teorias, na teoria de Engelhardt, por exemplo, o princípio tem uma base contratualista e de liberdade ao extremo, por basear-se em Rawls; e na teoria de Beauchamp, não existe uma prioridade visível, por basear-se na autonomia do Relatório Belmont e nos princípios prima facie obrigatórias de Ross.

As duas teorias sofrem severas críticas, mas somente a de Beauchamp recebe elogios e ainda ajuda no desenvolvimento de outras teorias, enquanto a de Engelhardt Jr. se mantém somente dentro do âmbito dos libertarianos e, fora deste âmbito, sofre críticas pesadas, como esta de Seifert:

A posição, contudo, na qual se reconhece uma ética secular, conhece apenas o domínio dos grupos religiosos, mas nega isso para qualquer ética pública, devendo ser chamado em certo sentido de AIDS filosófica da medicina, porque isto não determina o sistema imunológico filosófico e a resistência natural do intelecto humano para a praga da valoração relativista que divorcia completamente a medicina de seu pré-dado campo e ameaça a existência da medicina. (SEIFERT, 2004, p. 241).

A autonomia de Engelhardt, em certo sentido não pode governar sozinho o âmbito da bioética, pois isso poderia acarretar uma série de comportamentos imorais - ilícitos, nos quais estes atos não poderiam ser explicados como racionais e, por isso mesmo, seriam ilícitos, porque um ato correto moralmente deve ser possível de se poder mostrar/descobrir sua verdade ou falsidade, pela própria razão, da qual Engelhardt Jr. chama a todo o momento para se explicar, mas que não aceita que se é possível racionalmente chegar a atos moralmente corretos, mas de acordo com Kant as pessoas devem, sim, chegar a ver claramente o que é correto moralmente (KANT, 2001, p. 80).

Todas as pessoas são livres para realizar qualquer ato que desejem, mas sempre é necessário ter em mente as formas de distinguir se uma certa ação é correta ou não; não porque devemos simplesmente realizar ações corretas, mas sim, porque qualquer ação correta pode ser descoberta pela razão e assim servir de guia que oriente os passos da ação. 
A partir do que foi exposto no presente trabalho podemos concluir que os dois princípios em questão são diferentes já na sua estrutura de fundamentação. $\mathrm{O}$ princípio de respeito à autonomia tem uma base não tanto filosófica, mas sim baseada no Relatório Belmont e na teoria de W. Ross; enquanto que o princípio de permissão tem uma base um pouco mais filosófica, partindo de Kant, passando pelo contratualismo de Locke e tomando sua forma quase que final no trabalho de Rawls.

Os dois sistemas são pobres de fundamentação filosófica. A estrutura montada por cada um na teoria correspondente faz com que os princípios ganhem status diferentes. Em Engelhardt, o princípio de autonomia é o coração da teoria, enquanto que em Beauchamp e Childress, é mais uma peça sem um valor principal ou sequer uma prioridade.

Os conceitos de derivação de direitos nas duas teorias se fazem completamente distintos. Na de Engelhardt, se funda os direitos mais importantes no princípio de permissão, enquanto que no outro o princípio de respeito da autonomia só tem alguns direitos derivados que se podem perder quando algum outro princípio tem maior relevância.

A quem se aplica: Engelhardt Jr. defende claramente o conceito de que somente as pessoas racionais podem usufruir deste princípio. Já Beauchamp e Childress dizem que todos tem o direito de usufruir deste princípio, mas de certa forma, alguns mais e outros menos.

Nos casos práticos fica evidente que estamos falando de duas teorias muito distintas. Enquando uma permite a tomada de decisões somente pensando na autonomia ou no consentimento, a outra parte do pressuposto de que nem sempre a autonomia deve prevalecer, amenizando alguns conflitos morais, fazendo com que as decisões tomadas de acordo com esta teoria sejam muito mais corretas do ponto de vista moral, porque pensa no sujeito como um ser autônomo que participa no mundo e que não pode viver baseado somente em si mesmo. Os outros princípios da teoria principialista fazem com que este sujeito encontre algo mais que não seja somente ele mesmo.

Nas máximas vemos outra diferença interessante. Engelhardt Jr. usa uma máxima que agrega obrigações junto à permissão e também tenta, por meio desta, evitar que se entre em outros princípios como a beneficência.

Em Beauchamp, a máxima é negativa e não obriga por completo como a de Engelhardt, mas tem em seu fundo a idéia de proteger o sujeito, fazendo com que este respeite a autonomia do próximo e de certa forma faz também com que ele respeite a sua própria autonomia. 
No decorrer deste trabalho percebemos como algumas poucas diferenças fazem com que um princípio se transforme em, praticamente, dois completamente distintos e entre si mesmos conflitantes, não podendo estar juntos em uma mesma ação.

As críticas feitas a estes autores são vastas, representando uma alta influência das duas teorias, mas após análise por meio deste trabalho, o leitor poderá ao menos ter uma visão mais crítica dos dois sistemas e até de outros, pois muitos se baseiam em princípios ou na própria autonomia. Críticas sempre existirão, não importando o trabalho ou que ele defende.

Aqui não quero defender nenhuma das duas correntes bioéticas analisadas, mas sim fazer com que tenhamos mais instrumentos de análise dos métodos que usamos em comitês de ética em pesquisa, ou comitês de bioética. Esses sistemas podem não ser perfeitos, fechados, ou com uma grande estrutura filosófica de base, mas de certa forma a praticidade dos mesmos faz com que eles se tornem muito usados e assim também mais criticados.

A idéia dos dois autores é uma teoria que seja capaz de unir os estranhos morais entre si. Parece que, neste sentido, os dois conseguem desenvolver uma idéia muito boa de teoria, mas no fundo acabam por não conseguir reunir os estranhos morais, ficando ambos apenas na teoria em que se basearam. No caso de Beauchamp, de certa forma, parou no seu consequencialismo; e Engelhardt Jr. em sua teoria parte de Rawls e acaba voltando a ele. Não conseguindo, neste caso, nenhum dos dois cumprir por completo suas esperanças de um sistema que pudesse unir os estranhos morais.

\section{Referências}

BARRERA, J. M. La razón bioética y sus limites. Santiago: Universidad Católica de Santa Fe, 2001.

BEAUCHAMP, T. L.; CHILDRESS, J. F. Princípios de ética biomédica. 4. ed. São Paulo: Loyola, 2002.

BEAUCHAMP, T. L.; MCCULlOUGH, L. B. Ética médica: las responsabilidades morales de los médicos. Barcelona: Labor S. A., 1987. 
BLÁZQUEZ, N. Bioética: la nueva ciéncia de la vida. Barcelona: Biblioteca de Autores Cristianos, 2000.

DURANT, G. Introdução geral à bioética. São Paulo: Loyola, 2003.

ENGELHARDT Jr., H. T. The foundations of bioethics. New York: Oxford University Press, 1996.

GERT, B.; CULVER, C. M.; CLOUSER, K. D. Bioethics a return to fundamentals. New York: Oxford University Press, 1997.

GRACIA, D. ¿Qué es un sistema justo de servicios de salud? princípios para la asignación de recursos escassos. In: Washington: OPS, 1990. n. 57, p. 187-201.

Bioética: temas y perspectivas.

GRACIA, D. Fundamentación y enseñanza de la bioética. Bogotá, Colombia: Búho, 1998.

HANSON, S. Engelhardt and children: the failure of libertarian bioethics in pediatric interactions. Kennedy Institute of Ethics Journal, v. 15, n. 2, p. 179-198, 2005.

KANT, I. Fundamentación de la metafísica de los costumbres. Madrid: Colleción Austral, 2001.

KOTTOW, M. H. Introducción a la bioética. Santiago, Chile: Universitaria, 1995. (Colección El mundo de las Ciencias).

KUCZEWSKI, M. Casuistry and principlism: the convergence of method in biomedical ethics. Theoretical Medicine and Bioethics, New York, v. 19, n. 6, p. 509-524, 1998.

LOLAS, F. Bioética. Santiago, Chile: Universitaria, 1998. (Colección Orientaciones en Ciencia, Tecnologia y Cultura).

MAPPES, T. A.; ZEMBATY, J. S. Biomedical ethics. $3^{\text {a }}$ ed. New York: McGraw-Hill, 1991.

PELLEGRINO, E. D. La relación entre la autonomia y la integridad en la ética médica. In: Organización Panamericana de la Salud. Bioética: temas y perspectivas. Washington: OPS, 1990. n. 57, p. 8-17. 
SANCHES, M. A. Bioética: ciência e transcendência. São Paulo: Loyola, 2004.

SEGRE, M.; SILVA, F. L.; SCHRAMM, F. R. O contexto histórico, semântico e filosófico do princípio de autonomia. Revista Bioética, São Paulo, v. 6, n. 1, p. 15-25, 1998. Disponível em: <http://www.portalmedico.org.br/revista/ bio1v6/conthistorico.htm>. Acesso em: 16 jul. 2006.

SEIFERT, J. The philosophical diseases of medicine and their cure. New York: Springer, 2004. (Philosophy and Ethics of Medicine; v. 1).

SGRECCIA, E. Manual de bioética. São Paulo: Diana, 1996.

URBAM, C. A. Bioética clínica. São Paulo: Revinter, 2003.

Recebido: 02/02/2008

Received: 02/02/2008

Aprovado: $25 / 05 / 2008$

Approved: 05/25/2008 